\title{
Erratum to: Arbuscular mycorrhizal symbiosis increases host plant acceptance and population growth rates of the two-spotted spider mite Tetranychus urticae
}

Daniela Hoffmann • Horst Vierheilig •

Petra Riegler $\cdot$ Peter Schausberger

Published online: 1 December 2010

(C) Springer-Verlag 2010

Erratum to: Oecologia (2009) 158:663-671

DOI 10.1007/s00442-008-1179-7

On page 664 (right hand column) of the original article the unit of weight (mg) is incorrect. The correct unit of weight is $\mathrm{g}$.

The online version of the original article can be found under doi:10.1007/s00442-008-1179-7.

D. Hoffmann $(\varangle) \cdot$ H. Vierheilig $\cdot$ P. Riegler $\cdot$ P. Schausberger Department of Applied Plant Sciences and Plant Biotechnology, Institute of Plant Protection, BOKU,

University of Natural Resources and Applied Life Sciences,

Peter Jordan Strasse 82, 1190 Vienna, Austria

e-mail: daniela.hoffmann@boku.ac.at

H. Vierheilig

Departamento de Microbiología, Estación Experimental de Zaidín, Consejo Superior de Investigaciones Científicas (CSIC),

Calle Prof. Albareda 1, 18008 Granada, Spain 